\title{
Reação de genótipos de Capsicum spp. à podridão do colo (Sclerotium rolfsii)
}

\author{
João Vitor Camargo Soares ${ }^{1}$; Jânia Lília da Silva Bentes ${ }^{1}$; Luadir Gasparotto ${ }^{2}$
}

${ }^{1}$ Universidade Federal do Amazonas/Faculdade de Ciências Agrárias. Av. Rodrigo Otávio, 6200. 69077-000, Manaus-AM; ${ }^{2}$ Embrapa Amazônia Ocidental. Rodovia AM010, s/n, Km 29. 69010-970

Autor para correspondência: Jânia Lília da Silva Bentes(jlbentes@ufam.edu.br)

Data de chegada: 03/05/2016. Aceito para publicação em: 16/09/2016.

\section{RESUMO}

Soares, J.V.C.; Bentes, J.L.S.; Gasparotto, L. Reação de genótipos de Capsicum spp. à podridão do colo (Sclerotium rolfsii). Summa Phytopathologica, v.43, n.1, p.58-59, 2017.

Espécies do gênero Capsicum nativas da Amazônia são desconhecidas cientificamente e são potenciais fontes de genes de resistência aos problemas fitossanitários. A podridão do colo causada pelo fungo Sclerotium rolfsii Sacc. é uma das doenças mais comuns em cultivos pimentão no Amazonas, causando a perda plantas em campo e em cultivo protegido. O Objetivo deste trabalho foi avaliar a resistência de 18 genótios de Capsicum nativos da Amazônia à podridão do colo. Os experimentos foram conduzidos em casa de vegetação, em delineamento inteiramente casualizado, com três repetições. As inoculações foram realizadas por meio da deposição de três discos de meio de cultura contendo a colônia do patógeno em contato com o colo da planta aos 35 dias após a semeadura. A severidade foi avaliada de acordo com uma escala descritiva do progresso dos sintomas da doença. Foi calculada a área abaixo da curva de progresso da doença (AACPD) e as médias dos dados foram comparados entre si pelo teste de Tukey ( $\mathrm{P} \leq 0.05)$. Os genótipos MA03, BC16, LA02, TBT01, MA18, MA34, MA43, BC01, ATN01, IRB02, ATN02, ATN04, CDJ01, MA35 e MA37 comportaram-se como resistentes e apresentam potencial para futuros estudos de melhoramento genético de pimentas e pimentões para obtenção de cultivares resistentes à podridão do colo.

Palavras-chave: Pimentões, pimentas, resistência.

\section{ABSTRACT}

Soares, J.V.C.; Bentes, J.L.S.; Gasparotto, L. Reaction of Capsicum spp. genotypes to stem rot (Sclerotium rolfsii). Summa Phytopathologica, v.43, n.1, p.58-59, 2017.

Species of the genus Capsicum, native to the Amazon, are scientifically unknown and are potential sources of genes of resistance to phytosanitary problems. The stem rot caused by the fungus Sclerotium rolfsii Sacc. is one of the most common diseases in pepper crops in the Amazon, causing the loss of plants in the field and in greenhouse. The aim of this study was to evaluate the resistance of 18 genotypes of Capsicum native to the Amazon to stem rot. The experiments were carried out in a greenhouse in a completely randomized design with three replicates. Inoculations were performed by depositing three

Keywords: Chili, pepper, resistance. discs of culture medium containing the colony of the pathogen in contact with the collar region of the plant at 35 days after sowing. Disease severity was evaluated according to a descriptive scale of disease symptoms progress. The area under the disease progress curve (AUDPC) was calculated, and means of data were compared according to Tukey's test $(\mathrm{p} \leq 0.05)$. The genotypes MA03, BC16, LA02, TBT01, MA18, MA34, MA43, BC01, ATN01, IRB02, ATN02, ATN04, CDJ01, MA35 and MA37 behaved as resistant and have the potential for future studies on pepper and chili breeding to obtain cultivars resistant to stem rot.
As espécies silvestres afins às plantas cultivadas representam verdadeiros reservatórios de genes úteis que podem ser devidamente explorados, se transferidos para as espécies cultivadas. Espécies do gênero Capsicum são potencias fontes de genes de resistência aos problemas fitossanitários e precisam ser caracterizadas quanto ao seu desempenho agronômico e resistência à doenças e pragas .

Aárea cultivada com pimentas e pimentões no estado do Amazonas na safra 2013/2014 foi de 458,20 ha, envolvendo 3.964 produtores, com uma produção estimada de $8.411,44$ ton ha $^{-1}$ (6). Apesar dos avanços incorporados ao sistema de produção da cultura, observa-se uma baixa produtividade na região que pode estar relacionada com fatores fitossanitários.

A reação de espécies do gênero Capsicum a doenças tem sido alvo de diversos estudos visando a detecção de fontes de resistência. Babu et al. (2) selecionaram fontes de resistência em Capsicum contra alguns patógenos. Para o patossistema Capsicum - S. rolfsii, são poucos os estudos realizados para identificar fontes de resistência

A podridão do colo causada por Sclerotium rolfsii Sacc é uma das principais doenças que afetam os cultivos de pimentões na região, tanto a campo como em cultivo protegido. É uma doença de difícil controle devido ao longo período de sobrevivência do fungo no solo, ampla gama de hospedeiros, falta de cultivares resistentes e de controle químico recomendado (7). Este trabalho teve o objetivo de avaliar a resistência de genótipos de Capsicum spp. do Amazonas à podridão do colo.

Foram avaliados 18 genótipos de Capsicum pertencentes à coleção da Faculdade de Ciências Agrárias da Universidade Federal do Amazonas: MA0, MA18, MA19, MA31, MA34, MA35, MA37 e MA43 oriundos de Manaus, IRB02 de Iranduba, CDJ01 de Codajás, AN03 de Anorí, LA02 de Lábrea, BC01 de Benjamim Constant, ATN01, ATN02 e ATN04 de Atalaia do Norte, SGC15 de São Gabriel da Cachoeira e TBT01 de Tabatinga. A cultivar comercial de pimentão Nathalie, considera suscetível, serviu de testemunha. Somente o genótipo MA03 pertence à espécie C. baccatum, os demais são C. chinense e foram identificados e caracterizados agronomicamente por Costa et al. (4).

A semeadura foi realizada diretamente em sacos de polietileno de $0,5 \mathrm{~kg}$ de capacidade, utilizando-se como substrato latossolo argiloso 
autoclavado. A correção da acidez foi realizada adicionando-se 2,87 $\mathrm{g}$ de calcário dolomítico $\mathrm{kg}^{-1}$ de substrato de acordo com a análise química do solo.

Foram obtidos dez isolados de S. rolfsii (PR01 e IN02; IR01, IR02 e IR03; PF02, PF03, PF04, PF05 e PF06) obtidos a partir de plantas de pimentão com sintomas típicos da doença, coletados nos municípios de Manaus, Iranduba e Presidente Figueiredo, respectivamente, do estado do Amazonas. O isolamento foi realizado pelo método direto (1) em placas de Petri, contendo o meio de cultura BDA (batata-dextroseágar). As colônias obtidas foram mantidas em incubadora BOD a 26 ${ }^{\circ} \mathrm{C}$ na ausência de luz. Para inoculação foi usado o isolado IR02 que apresentou maior agressividade média quando inoculado em plantas de pimentão da cultivar Tibérius e Nathalie

As plantas foram inoculadas aos 35 dias após a semeadura, por meio da deposição de três discos de meio de cultura BDA contendo a colônia do patógeno, com dez dias de idade, em contato com o colo de cada planta sem ferimento. Após a inoculação, as plantas foram mantidas em câmara úmida durante 48 horas em seguida as plantas foram mantidas em casa de vegetação. Foi realizado o re-isolamento do patógeno a partir das plantas inoculadas.

$\mathrm{O}$ delineamento experimental foi inteiramente ao caso, com e três repetições sendo cada unidade experimental constituída por uma planta. Como testemunha foram consideradas plantas de cada genótipo inoculadas com três discos de meio de cultura BDA sem o patógeno, depositados em contato com colo de cada planta.

O progresso dos sintomas foi avaliado em dias alternados, durante 30 dias, através de uma escala de notas proposta por Pastor-Corrales \& Abawie (8), variando de 1 a 9 onde: 1 - planta sem sintomas da doença; 3 - planta com $10 \%$ de folhas murchas e pequenas lesões no colo; 5 - planta com 50\% de folhas murchas, clorose e necrose; 9 - Necrose seguida de desfolha precoce e mais de $75 \%$ de murcha ou planta morta.

Foi calculada a área abaixo da curva de progresso da doença (3). Os dados obtidos foram submetidos à análise de variância e as médias comparadas pelo teste de Tukey ao nível de 5\% de probabilidade utilizando o programa ASSISTAT 7.6 Beta.

Os genótipos de Capsicum spp. avaliados apresentaram reações distintas à doença (Tabela 1).

Os genótipos MA03 (C. baccatum), BC16, LA02, TBT01, MA18, MA34, MA43, BC01, ATN01, IRB02, ATN02, ATN04, CDJ01, MA35 e MA37 (C. chinense) apresentaram os menores valores de AACPD e foram considerados resistentes à doença. Os genótipos AN03, MA31 e SGC15 e a cultivar Nathalie, apresentaram valores intermediários de AACPD. O genótipo MA19 foi o mais suscetível.

Em trabalho semelhante a este Fery \& Dukes (5) avaliaram a herança de resistência à podridão do colo nas cultivares de pimentão Golden California Wonder (resistente) e Sweet Banana (suscetível) para o desenvolvimento de cultivares resistentes e concluíram que a resistência é conferida por um único gene recessivo que apresenta potencial para uso no melhoramento genético.

Considerando que a região amazônica é um importante centro de diversidade do gênero Capsicum, os genótipos MA03, BC16, LA02, TBT01, MA18, MA34, MA43, BC01, ATN01, IRB02, ATN02, ATN04, CDJ01, MA35 e MA37 que apresentaram resistência à podridão do colo, tem potencial para ser utilizados nos programas de melhoramento genético como fontes de genes de resistência.

\section{AGRADECIMENTO}

Ao Conselho Nacional de Desenvolvimento Científico e Tecnológico- CNPq pelo auxílio financeiro para a pesquisa.
Tabela 1. Área Abaixo da Curva de Progresso da Doença (AACPD) da podridão do colo (Sclerotium rolfsii) em genótipos de Capsicum spp.

\begin{tabular}{cc}
\hline Genótipos & AACPD \\
\hline AN03 (C.chinense) & $3640 \mathrm{~b}$ \\
MA31 (C.chinense) & $2957 \mathrm{~b}$ \\
MA19 (C.chinense) & $4566 \mathrm{a}$ \\
MA03 (C. baccatum) & $1447 \mathrm{c}$ \\
BC16 (C.chinense) & $1138 \mathrm{c}$ \\
LA02 (C.chinense) & $1436 \mathrm{c}$ \\
TBT01 (C.chinense) & $1535 \mathrm{c}$ \\
MA18 (C.chinense) & $1491 \mathrm{c}$ \\
MA34 (C.chinense) & $1193 \mathrm{c}$ \\
MA43 (C.chinense) & $1293 \mathrm{c}$ \\
BC01 (C.chinense) & $1436 \mathrm{c}$ \\
ATN01 (C.chinense) & $1127 \mathrm{c}$ \\
IRB02 (C.chinense) & $1574 \mathrm{c}$ \\
ATN02 (C.chinense) & $1028 \mathrm{c}$ \\
ATN04 (C.chinense) & $1392 \mathrm{c}$ \\
CDJ01 (C.chinense) & $1734 \mathrm{c}$ \\
MA35 (C.chinense) & $2185 \mathrm{c}$ \\
MA37 (C.chinense) & $1866 \mathrm{c}$ \\
SGC15(C.chinense) & $3056 \mathrm{~b}$ \\
Cultivar Nathalie (C. annuum) & $2902 \mathrm{~b}$ \\
\hline
\end{tabular}

Médias seguidas pela mesma letra não diferem entre si, pelo teste de Tukey $p$ $<0,05$ de probabilidade.

\section{REFERÊNCIAS}

1. Alfenas, A.C.; Ferreira, F.A.; Mafia, R.G.; Gonçalves, R.C. Isolamento de fungos fitopatogênicos. In: Alfenas, A.C.; Mafia R.G. (Ed.). Métodos em fitopatologia. Viçosa: Universidade Federal de Viçosa, 2007. p.53-90

2. Babu, S.B.; Pandravada, S.R.; Prasada Rao, R.D.V.J.; Anitha, K.; Chakrabarty, S.K.; Varaprasad, K.S. Global sources of pepper genetic resources against arthropds, nematodes and pathogens. Crop Protection, Guildford, v.30, p.389-400, 2011.

3. Campbell, C.L.; Madden, L.V. Monitoring epidemics: disease. In: Campbell, C.L; Madden, L.V. Introduction to plant disease epidemiology. New York: John Wiley \& Sons, 1990. p.107-128.

4. Costa, L.V.; Bentes, J.L.S.; Lopes, M.T.G., Viana Júnior, J.M. Caracterização de acessos de pimentas do Amazonas. Horticultura Brasileira, Brasília, DF, v.33, n.3, p.290-298, 2015.

5. Fery, R.L.; Dukes Sr, P.D. Potential for utilization of pepper germoplasm with a variable reaction to Sclerotium rolfsii Sacc. to develop southern blight-resistant pepper (Capsicum annuum L.) cultivars. Plant Genetic Resources, Cambridge, n.3, p.326-330, 2005.

6. Instituto de Desenvolvimento Agropecuário e Florestal Sustentável do Estado do Amazonas - IDAM. Departamento de Planejamento. Relatório de Atividades do IDAM. Manaus, 2014.

7. Lopes, C.A.; Ávila, A.C. Murcha de esclerócio (Sclerotium rolfsii). In: Lopes, C.A. Doenças do tomateiro. Brasília, DF: Embrapa Hortaliças, 2005. p.39.

8. Pastor-Corrales, M.A; Abawi, G.S. Reactions of selected bean germoplasm to infection by Fusarium oxysporum f.sp. phaseoli. Plant Disease, St. Paul, n.71, p. 990-993, 1987.

\section{ERRATA}

Onde se lia:

Palavras-chave: Laranja, tangerina, doenças dos citros, fungo.

Leia-se:

Palavras-chave: Pimentões, pimentas, resistência. 